$$
\text { صيانة المباني في مصر من و اقع التطور التكنولوجي }
$$

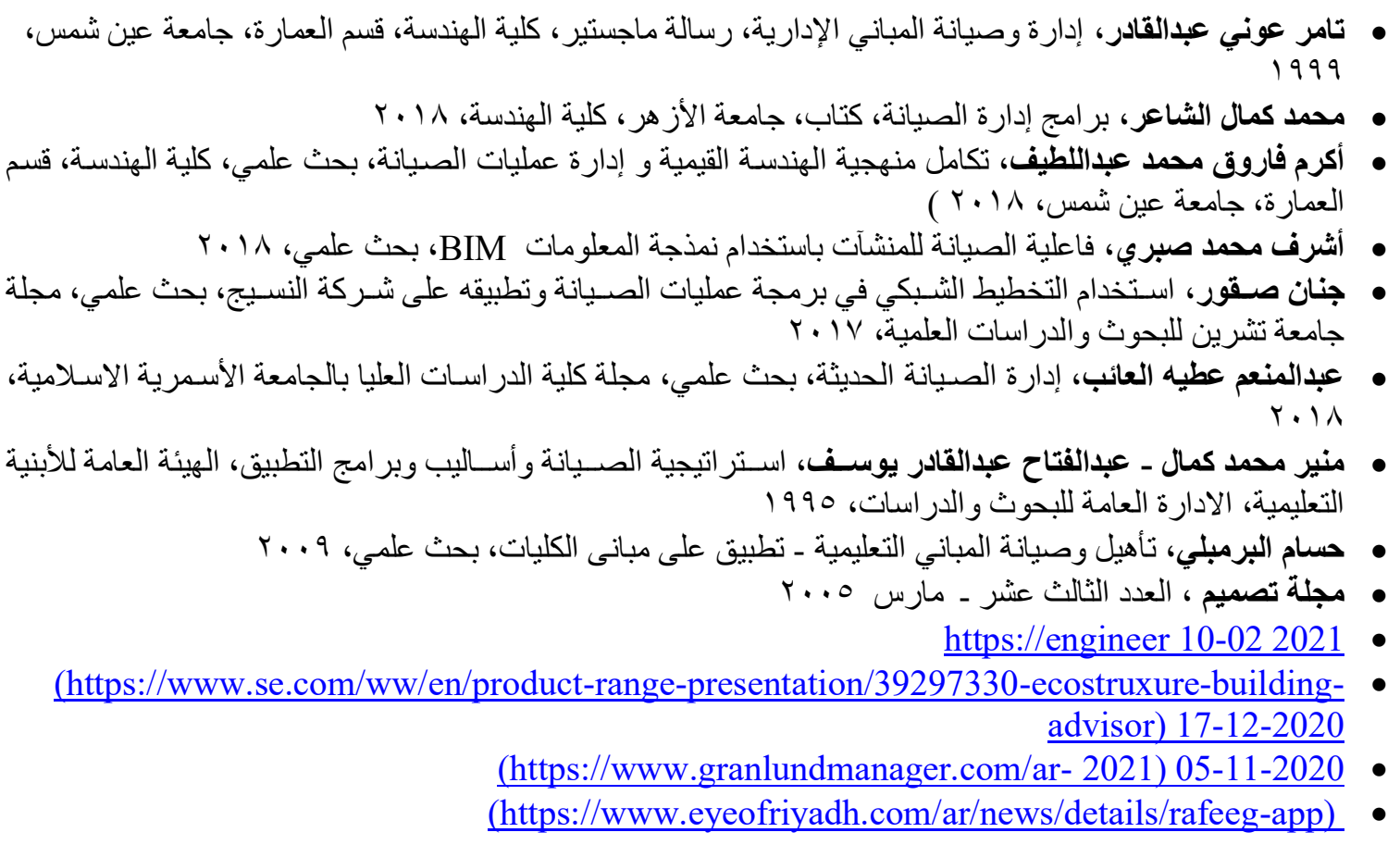




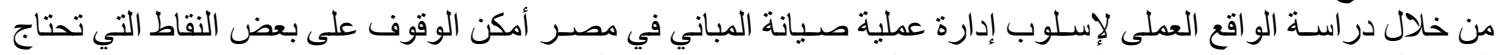

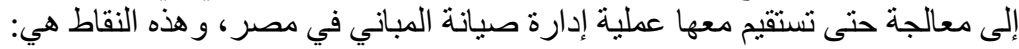

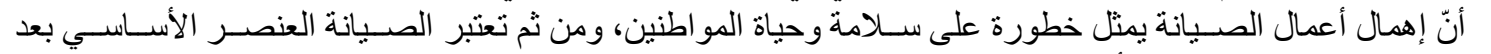

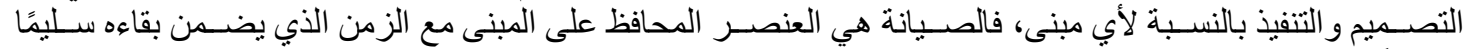

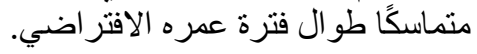

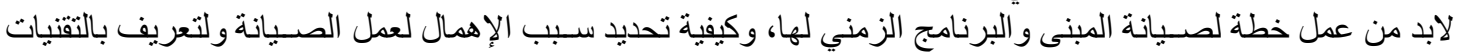

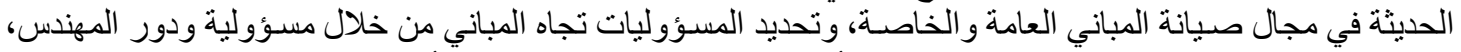

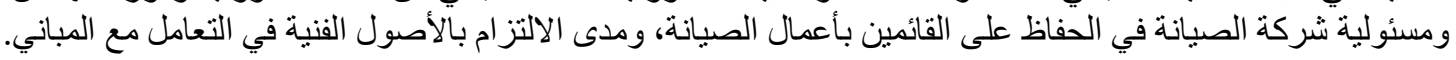

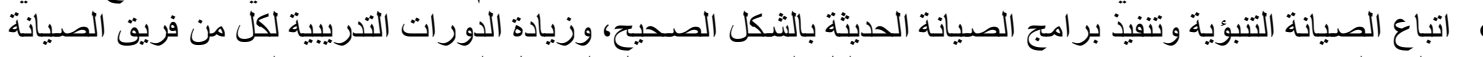

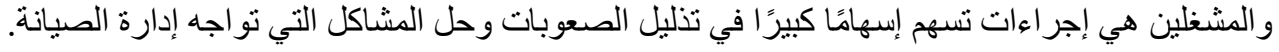

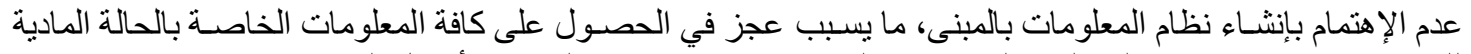

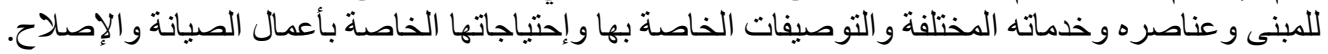

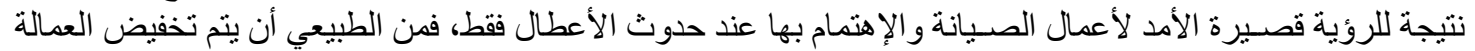

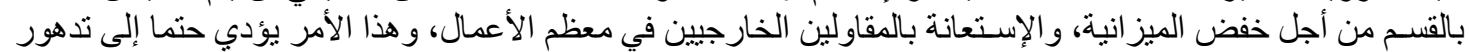

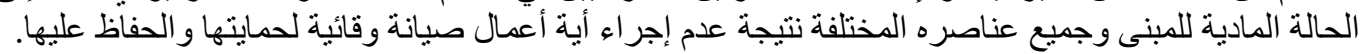

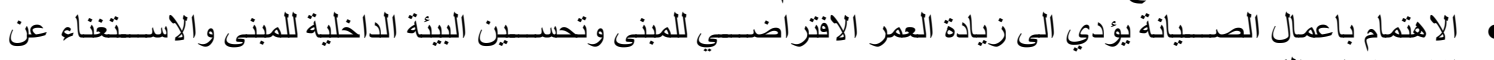
الاصلاحات الكبيرة.

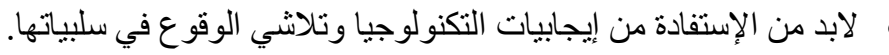

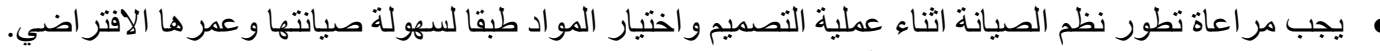

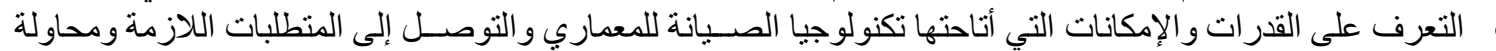

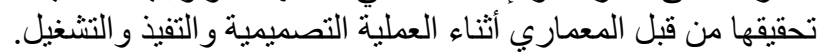

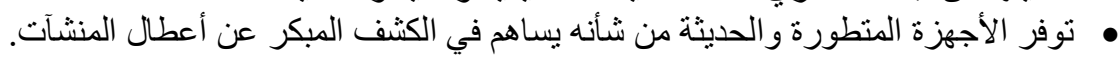

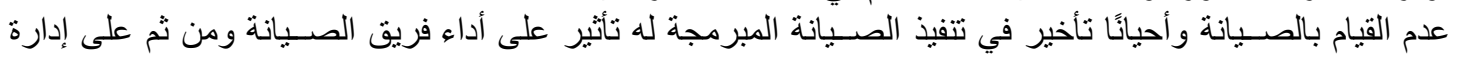
الصيانة. • • الدورات التدريبية لرفع كفاءة العمال من مشغلين وفنيي صيانة له مردود إيجابي على العملية الإنتاجية.

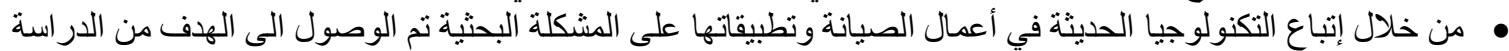
مما يؤكد الفرضية البحثية.

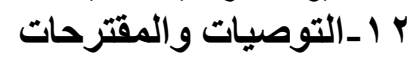

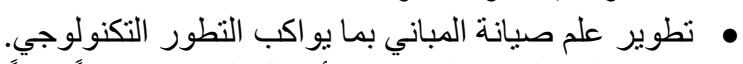

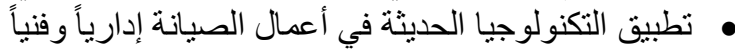

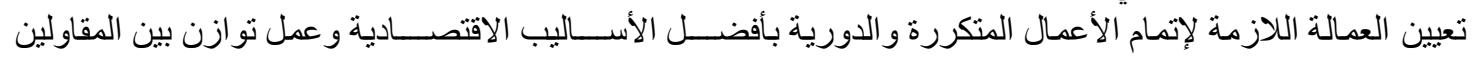
الخارجيين و العمالة المعينة.

ه تطبيق مقتر ح الباحث في إدارة وتنفيذ أعمال الصيانة.

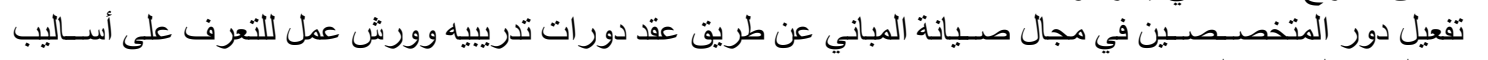

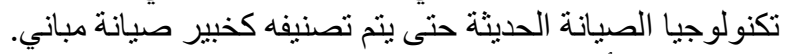

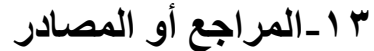

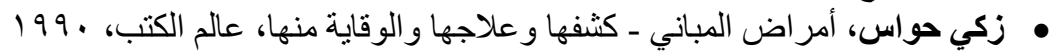

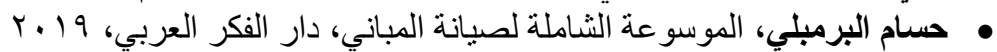
• شريف محمد العطار، صبانة المباني: مدخل لادارة وتخطيط أعمال صيانة المباني، رسالة ماجستير، كلية الهندسة، قسم العمارة، جامعة القاهرة، 1990 • محمد سـليمان منون، صـيانة المباني السـكنية: العو امل المؤثرة فى مرحلة التصـيم للتخفيض من حجم أعمال الصـيانة

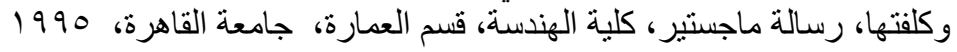

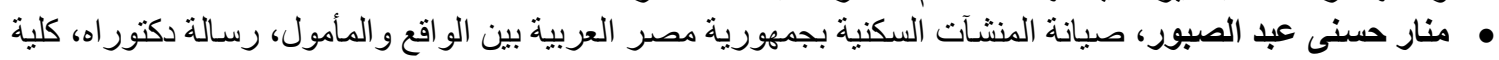

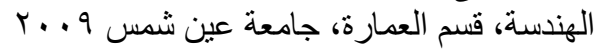


9 التوجهات الجديدة للاولة في الحفاظ على الثروة العقارية

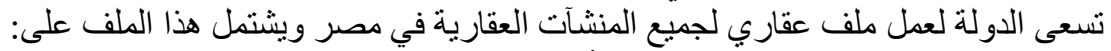

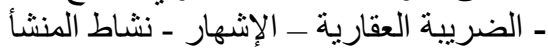

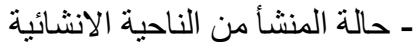

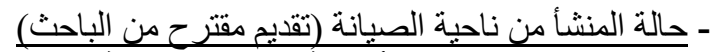

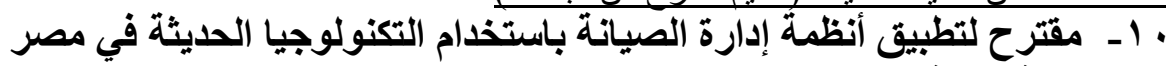

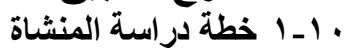

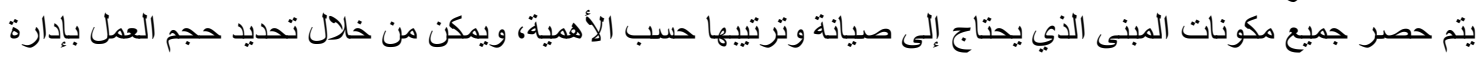

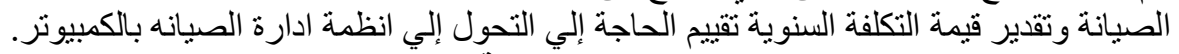

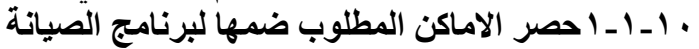

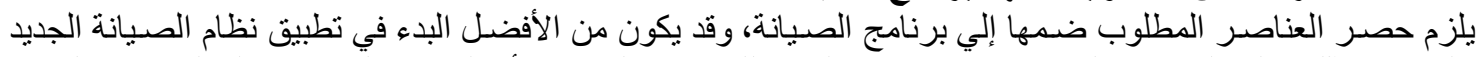

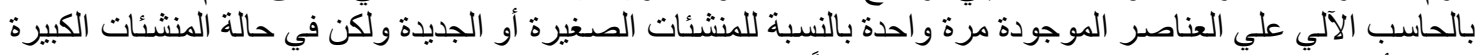

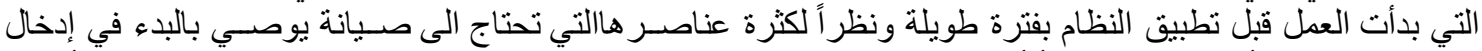

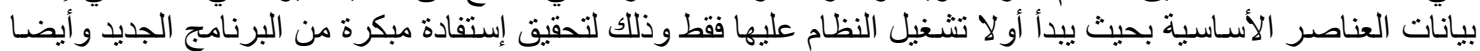

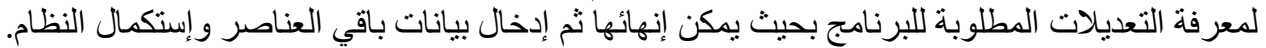

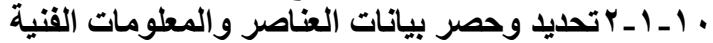

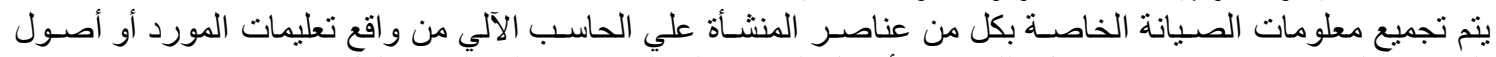

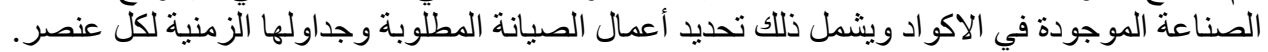

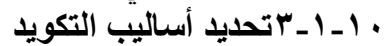
ويشمل الإتفاق علي تكويد العناصر ، تلكويد مهام الصبانة، تكويد العاملين ويجب أن يتم التكويد بأسلوب بسمح بالتوسع في

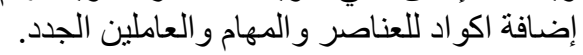

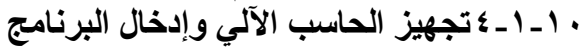

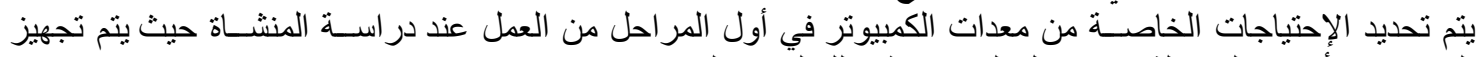

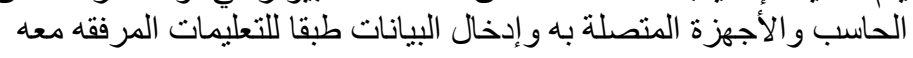

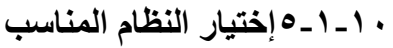

يوجد حاليا العديد من برامجار المطام الصيانة التي تم إستخدامها في الكثير من المنشئات الصناعية وتم تطوير ها علي مدار السنين الماضية و مطورة للتعامل باللغة الإنجليزية مثل: Maximo, MP2, SAP, MIMS, Main Smart

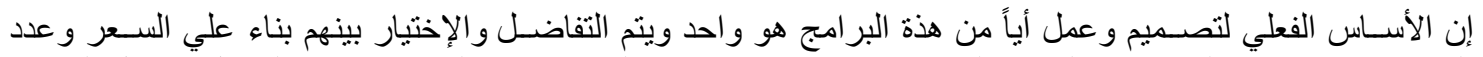

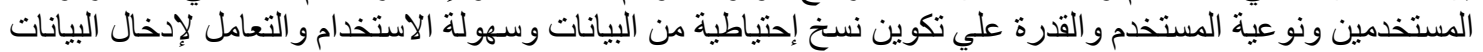

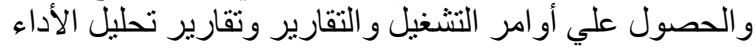

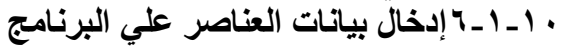

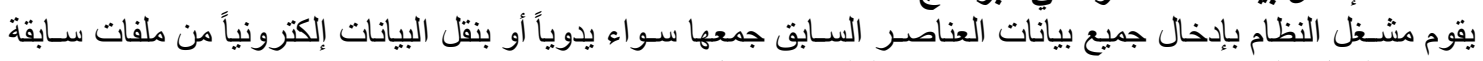

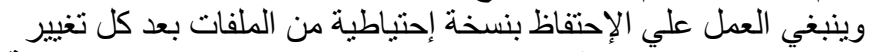

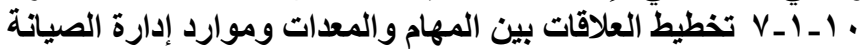

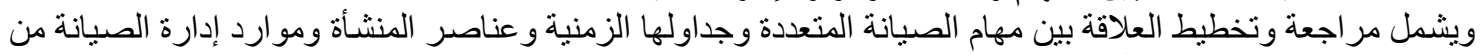
عاملين ومعدات وقطع غيار أو المقاولين في حالة إستخدامهرم

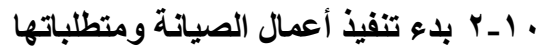

بعد إنهاء إدخال البيانات يكون النظام جاهزاً للعمل ويبقي إنتهاء التدريب للممارسـة الفعلية وبدء العمل الفعلي للنظام ويلزم لذلك :

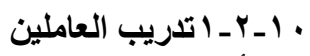

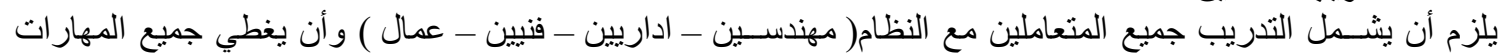

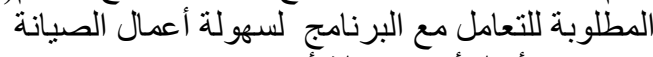

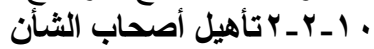
وذللك من خلال ورش عمل وعرض أب ومناق ومنتات و استبيان 


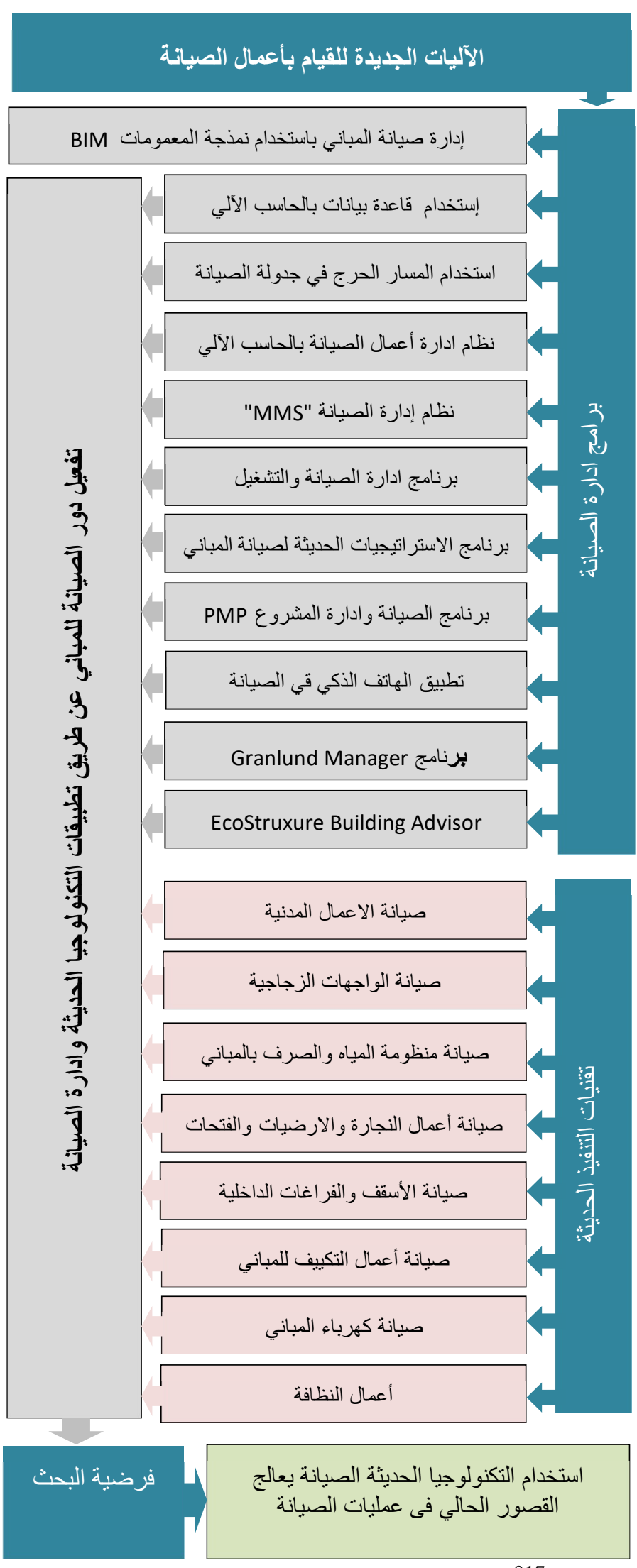

1 1 أعمال النظافة

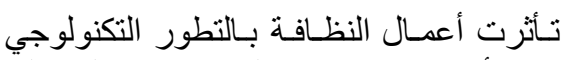

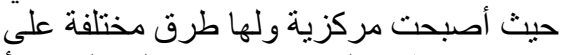
حســب وظيفة المبنى وفر اغاته المختلفة وبـ وبدأ العالم يهتم بهذا النوع من الصيانة الدورية بعد الدئ الظروف المسـتجدة (COVID19) فأصــبح

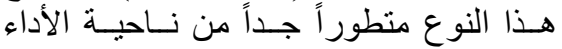
و الصوت و المجهود مقارنة بالنظام التقليدي .
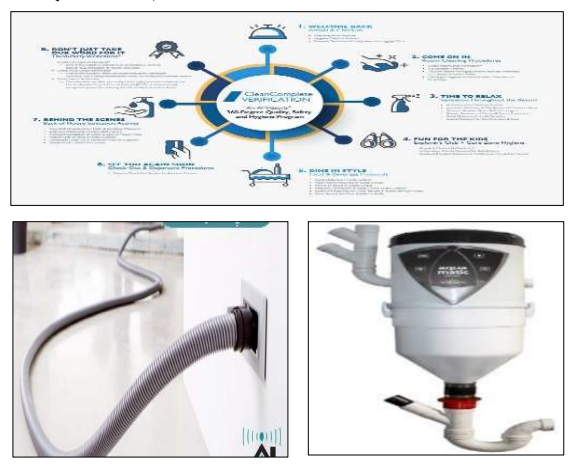

V-A

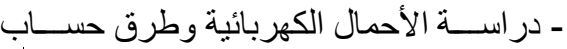
أقطار الأسلاكك و القو اطع و الحماية الكهربية

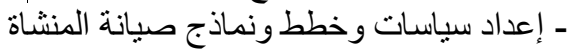

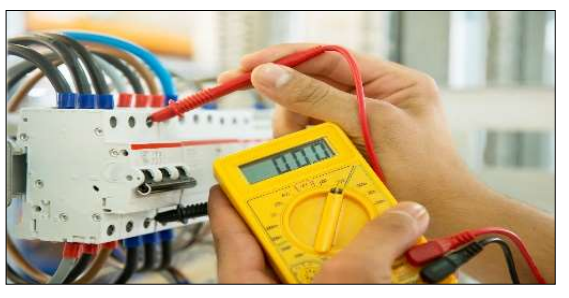

A_A

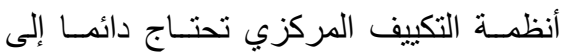

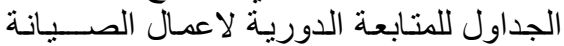
الدورية الوقائية فيوجد صيانة يو للورية و اسبو عية الدية

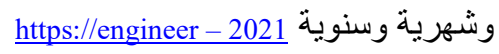
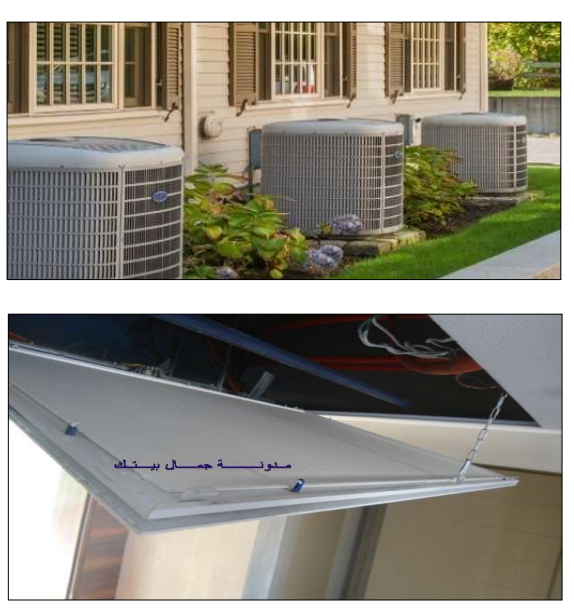

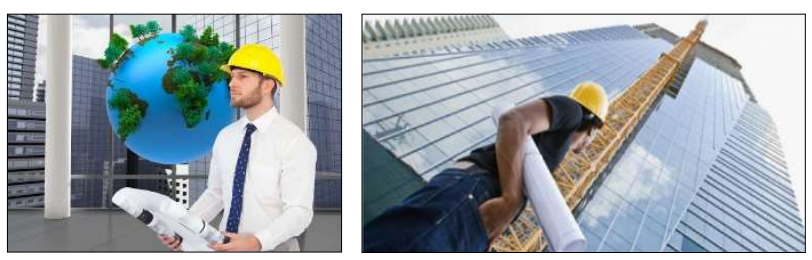

^ـتأثير التطور التكنولوجي فى تنفيذ أعمال الصيانة

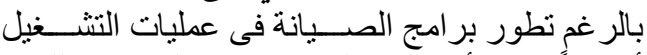

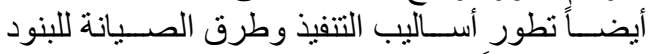

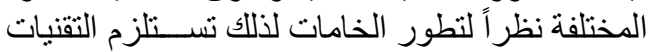

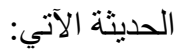

- در اسة مكونات المباني و المنشات و و حساب تكاليفها.

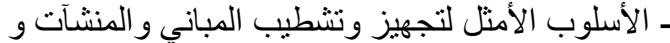
ذللك من الناحية الفنية و الاقتصادية. ـ دور مهندسي ومسئولي الصيانة فى المر احل المختلفة فى حياه المنشاة منذ التفكير فى الإنشاء حتى عملية الإحلال و التجديد.

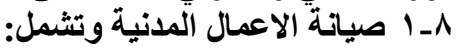
ـ الدباني و عمليات الترميج و أسالييها. ـ الدهانات و الطرق الفنية لإجر اءء عمليات الدهان الدان و التفنيش الدوري عليها. ـ الأساسات وطرق الكثف الدوري عليها.

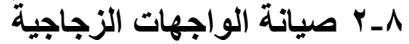

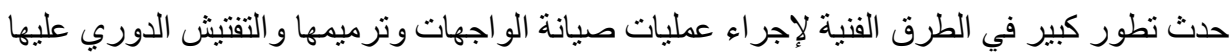
https://lengineer - 2021
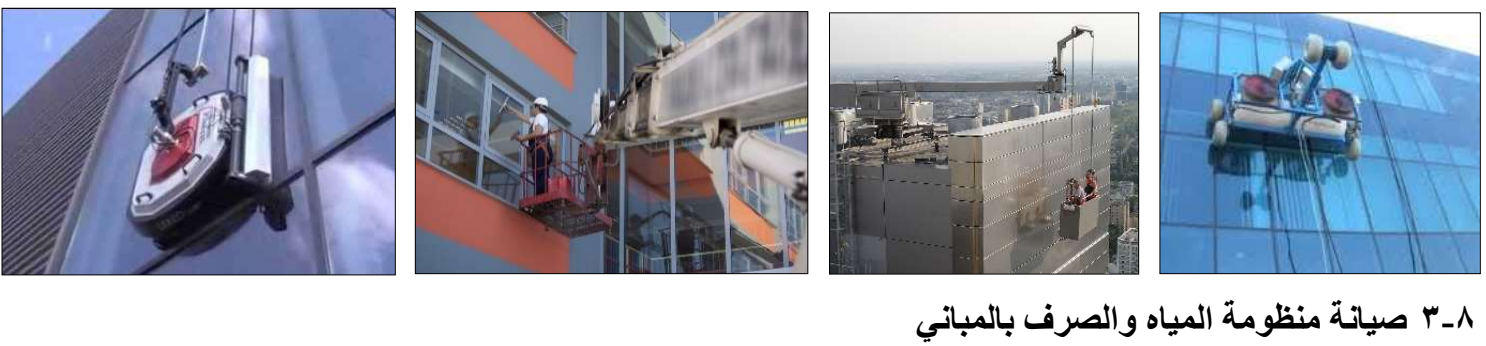

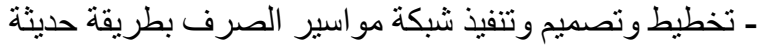

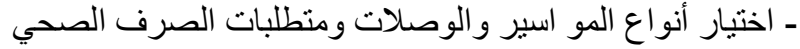

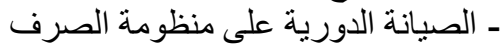
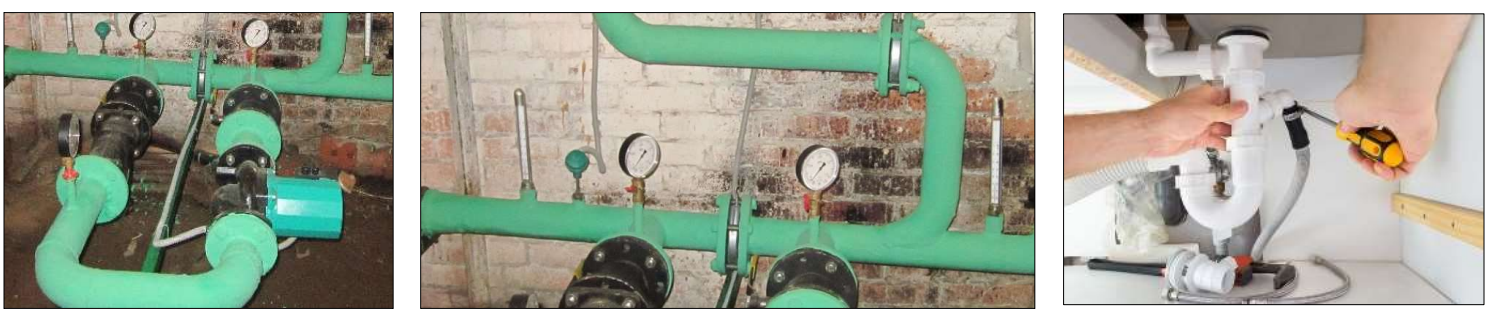

Aـ ـ صيانة أعمال النجارة والأثاث والارضيات و الفتحات
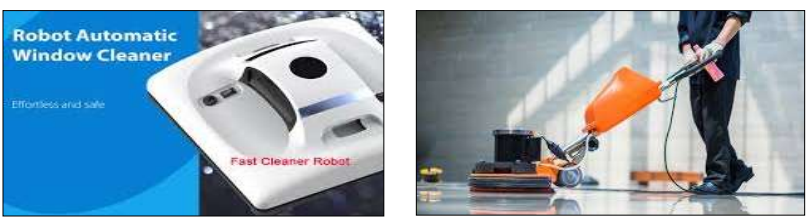

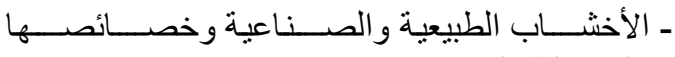

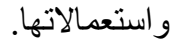

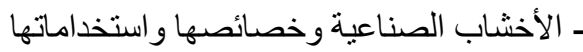

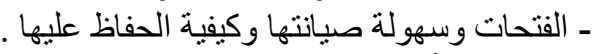

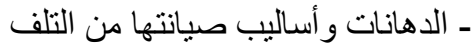

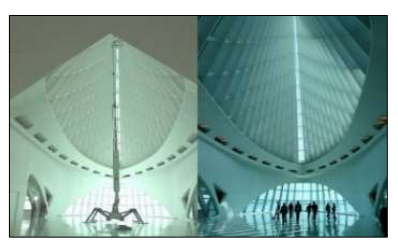

^ــ صيانة الأسقف و الفراغات الاخلية

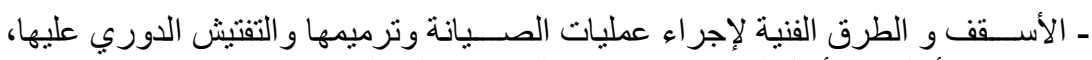
وتطبيق الأسلوب الأمثل لصبانة الاسقف و الفر اغات الفات الداخلية 


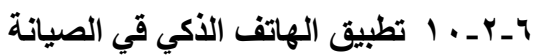

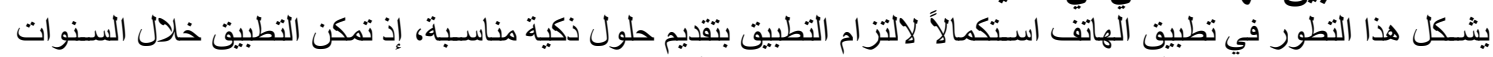

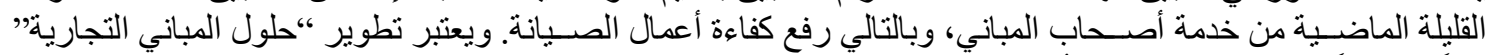

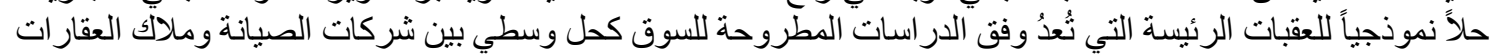

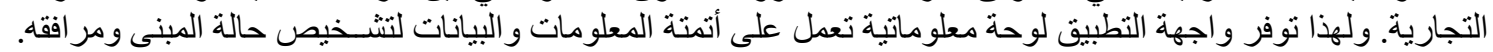

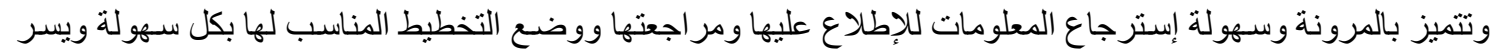
(https://www.eyeofriyadh.com/ar/news/details/rafeeg-app)

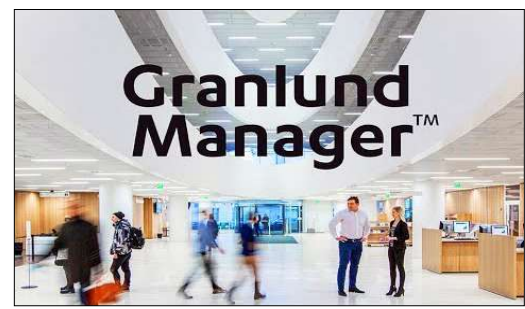

Granlund Manager برنامئ

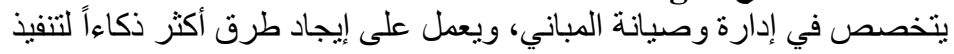

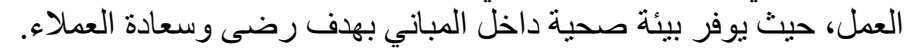

$$
\text { - صيانة أكثر سلاسة البرنامج بالاتي: }
$$

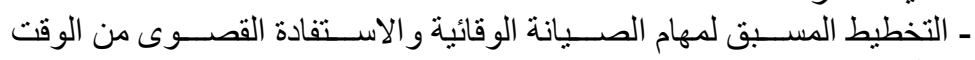
و الموارد

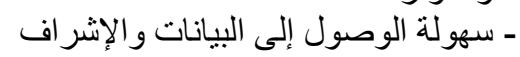

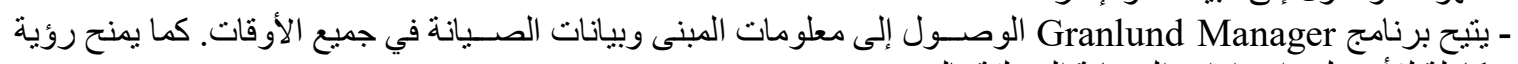

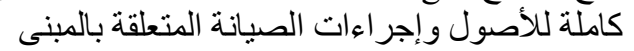

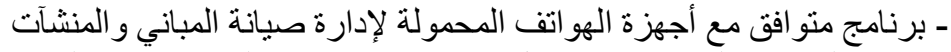

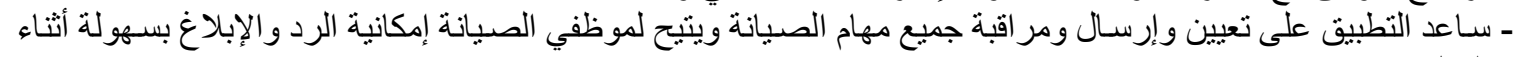
التنقل - يمكن تحويل المعلومات المعنية إلى تقارير بحسب احتياجات العميل أو المستخدم، بالإضافة إلى خاصية تحليل البيانات. https://www.granlundmanager.com/ar- 2021

\section{EcoStruxure Building Advisor $1 r_{-} r_{-} \uparrow$}

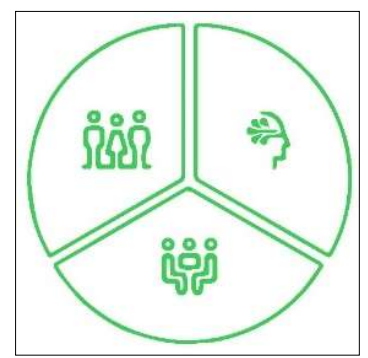

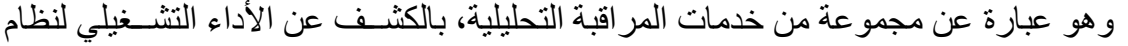

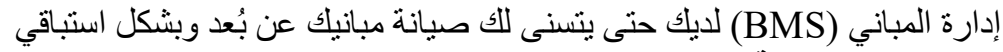
نهج متوازن لصيانة المبانى

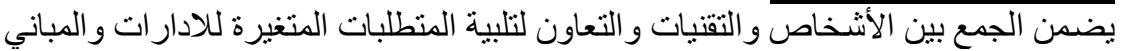

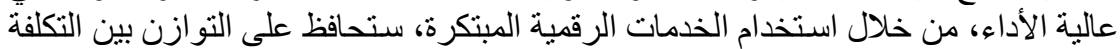
و المخاطر وقيمة الأصول مناهل (https://www.se.com/ww/en/product-range-presentation/39297330-ecostruxure-buildingadvisor)

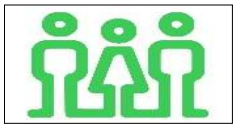

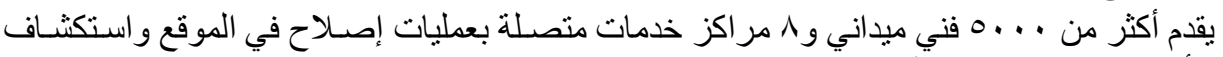

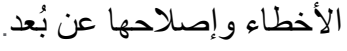

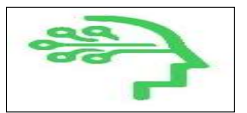

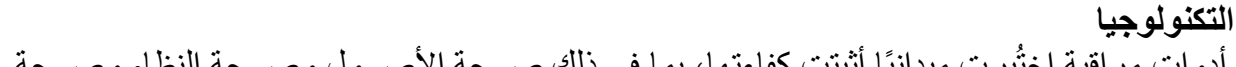

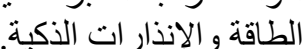
ضمان تحقيق أهداف شركتك من خلال نهجنا الاستشاري و التقارير الدورية ومشاركة المهام .

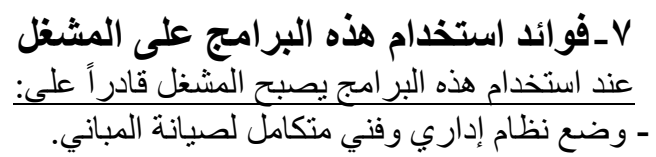

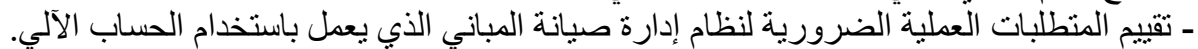

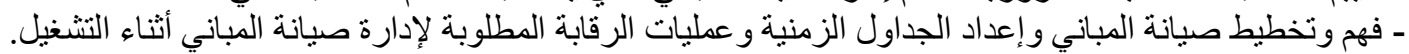

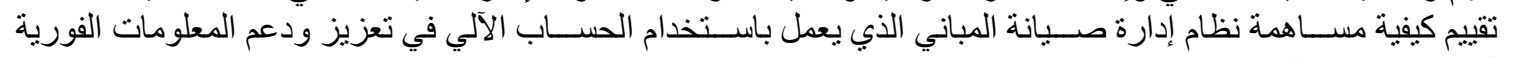

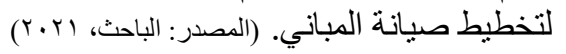




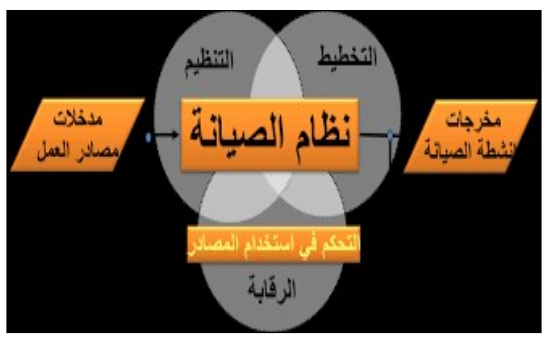

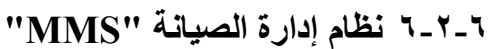

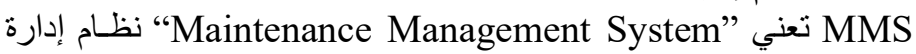

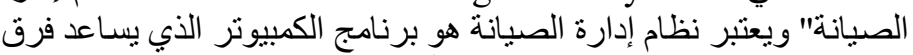

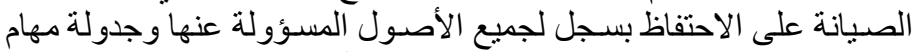

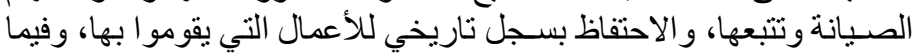

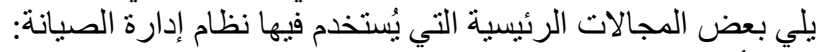

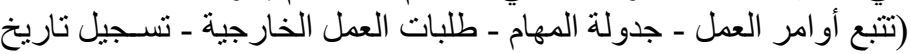
الأصول ـ إدارة المخزون ـ التدقيق و الاعتماد) (جاسم حسين زناد، إدارة الصيانة) - فوائد نظام إدارة الصيانة المحوسبة الدئة

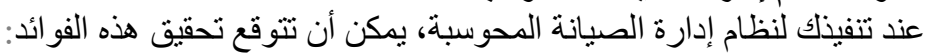

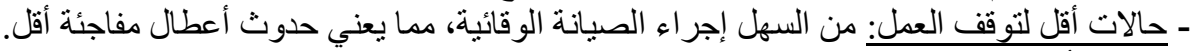

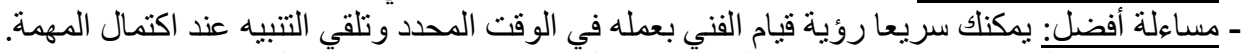

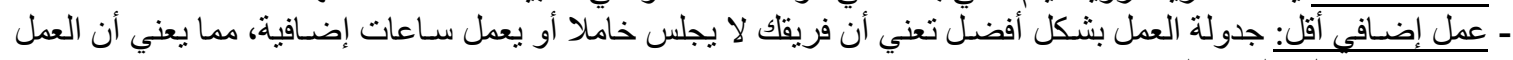
تم تقسيمه بشكل سليم وبالتساوي. - الحصول على المعلومات: يمكن للفنيين تسجيل المشاكل و الحلول، بحيث يتم تسجيل هذه المعلومات للآخرين لاستخدامها.

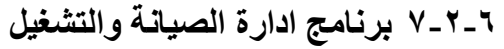

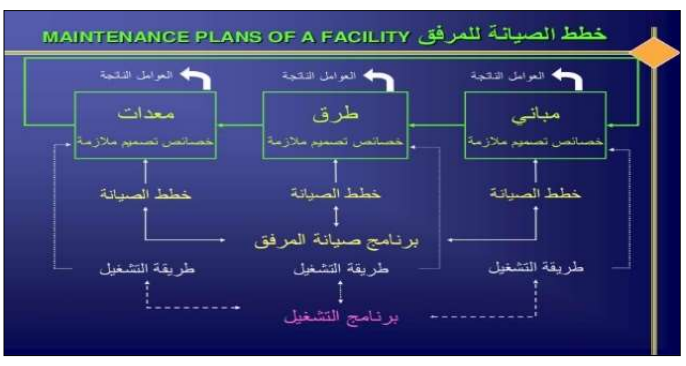

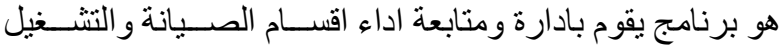

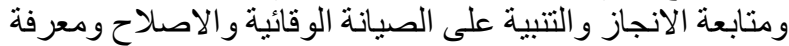

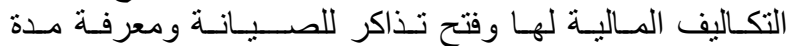

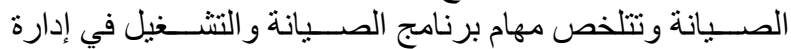

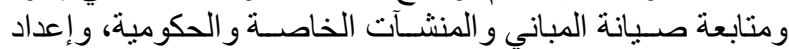

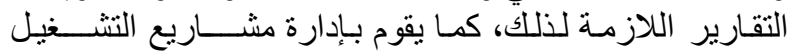

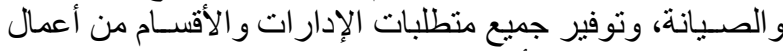

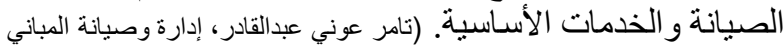

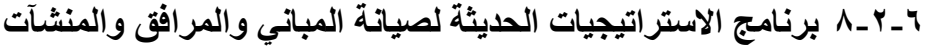

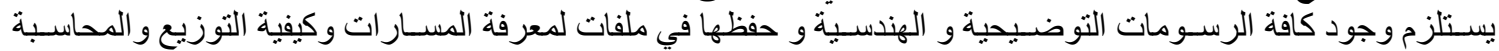

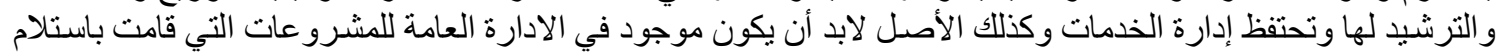

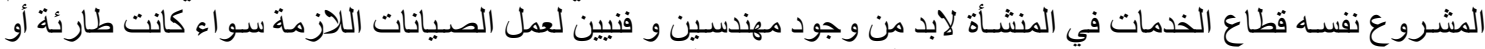

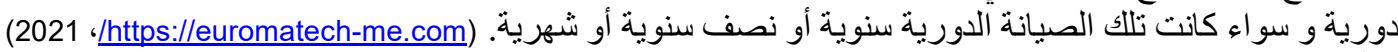
ـ أهداف البرنامج

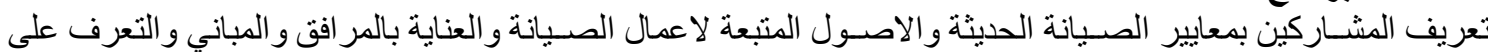

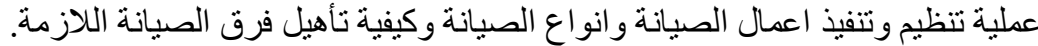

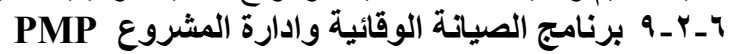

\section{The New PMP Flow in 2021!}

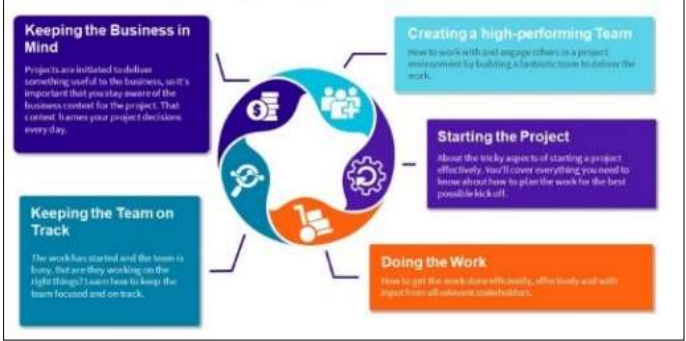

يقوم هذا البرنامج على الدئ الآتي:

ـ تحديد العناصر المر اد صيانتها.

تحديد جميع عمليات الصيانة من و اقع تعليمات الادارة.

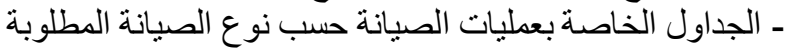
- 2 - استحداث خطة الصيانة. ـ اختيار وتدريب العمالة الفنية.

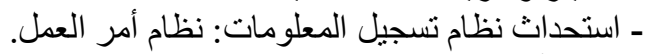

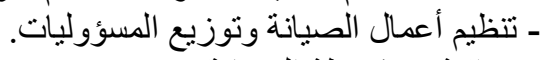

- مر اقبة تنفيذ خطة الصيانة. (2021 'https://hageritr.wixsite.com) 


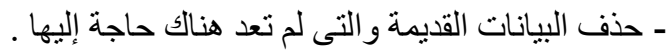

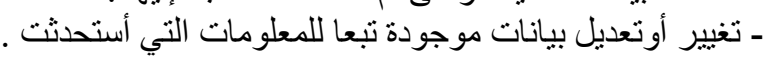

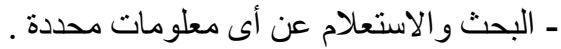

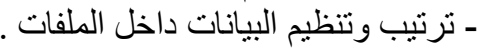

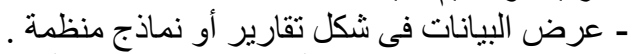

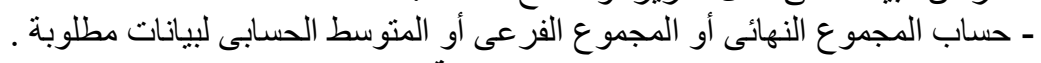

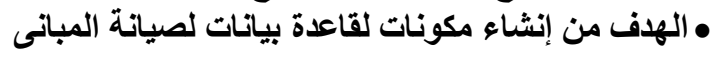

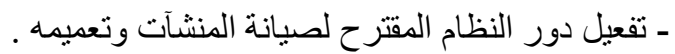

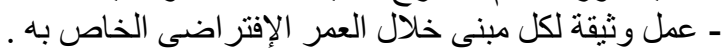

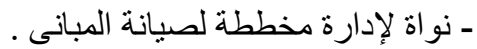

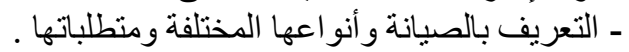

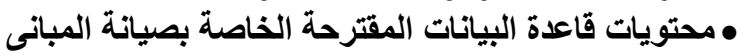

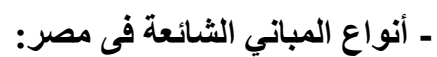

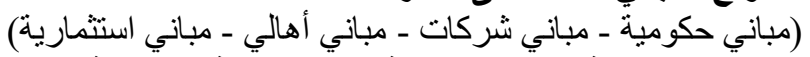

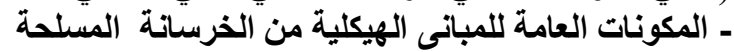

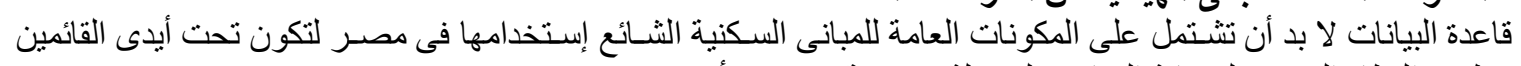

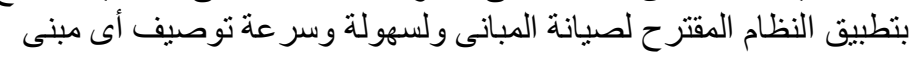

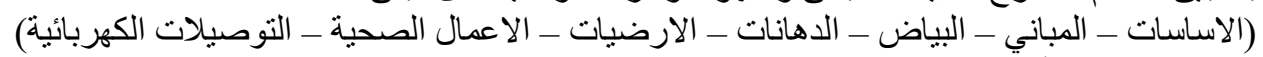

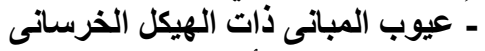

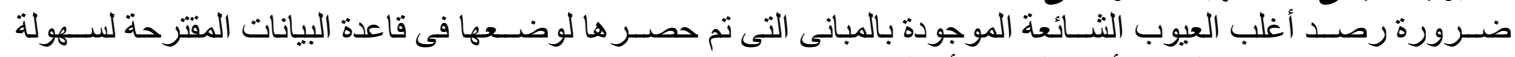

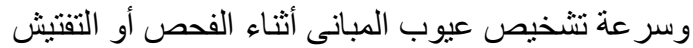

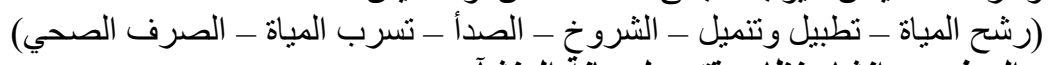

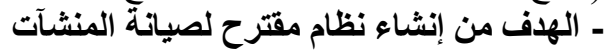

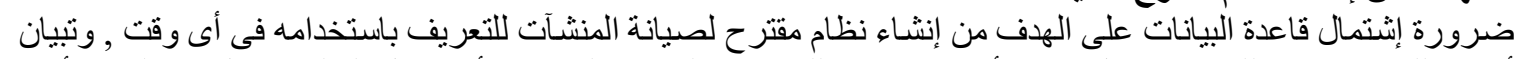

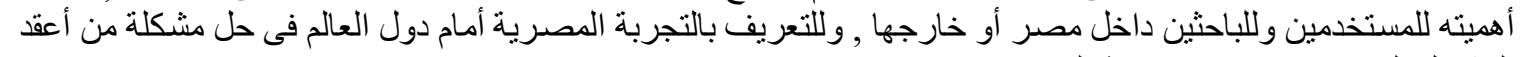
المشاكل التى و اجهتها و هلى صيانة المبانى.
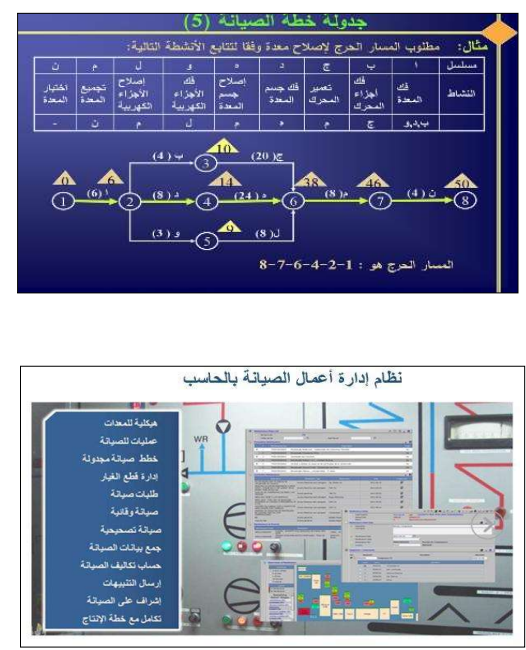

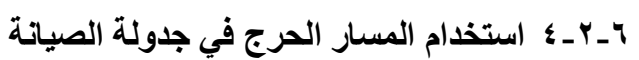
Application of CPM in Maintenance Scheduling هو برنامج يقوم بادارة نظم هندسة الصيانه الحديثة من خلال التعرف على نظم نظم

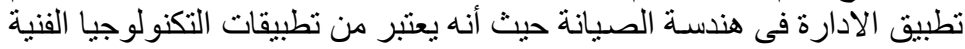

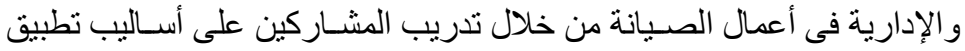

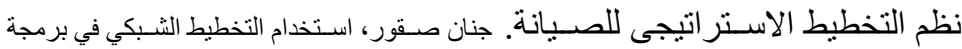

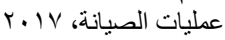

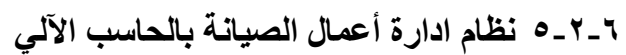

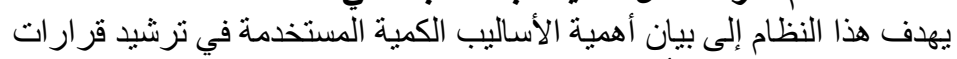

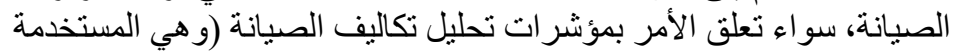

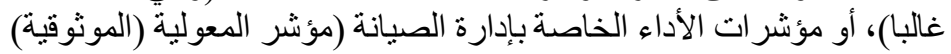

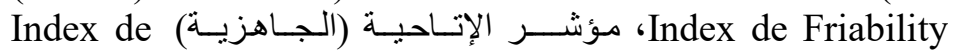

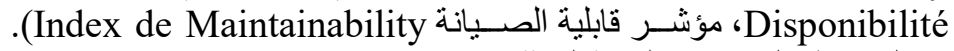
(عبدالنعم عطيه العائب، إدارة الصيانة الحديثة) 
• الصـيانة الوقائية (المخططة) : هى طريقة لحل مشـاكل و عيوب الصـيانة التصـحيحية، وذلك بو اسـطة التقليل من إحتمالية

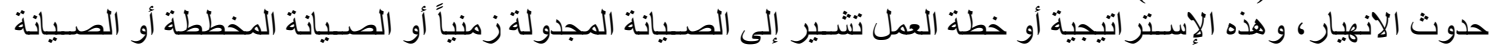

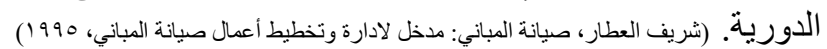

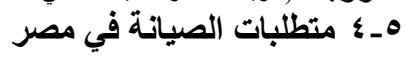

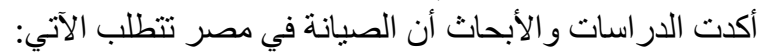

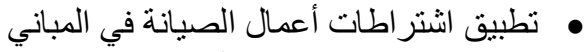

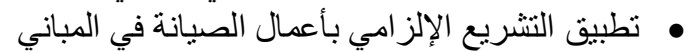

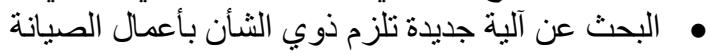

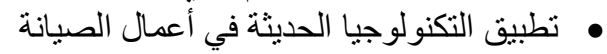

7ـ الآليات الجديدة للقيام بأعمال الصيانة

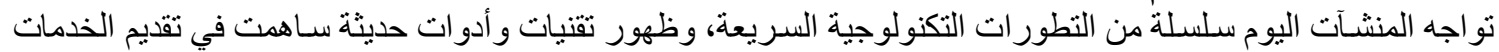

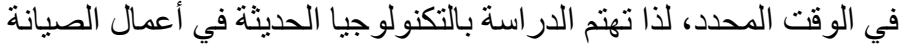

TECHNOLOGY مصطلح تكنولوجيا يعني تنظيم المهارة الفنية و المعرفة في تحقيق الأهداف و التغلب علي الصعوبات.

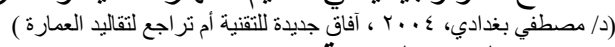

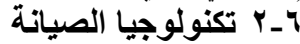

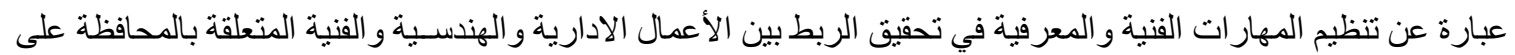

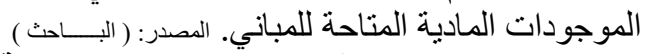

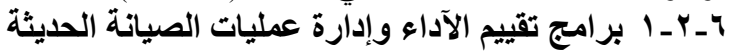

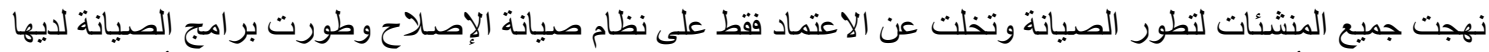

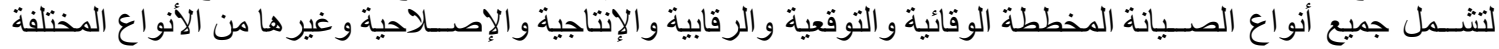

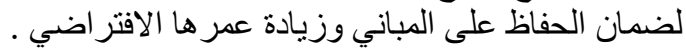

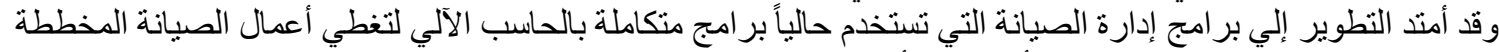

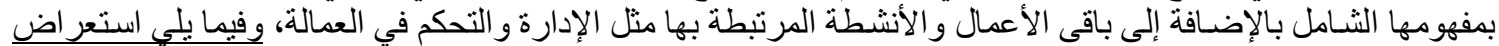

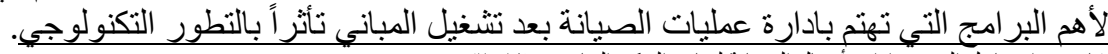

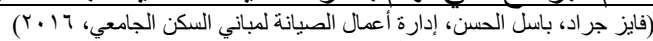

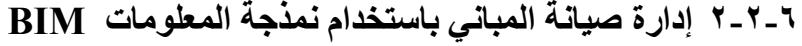
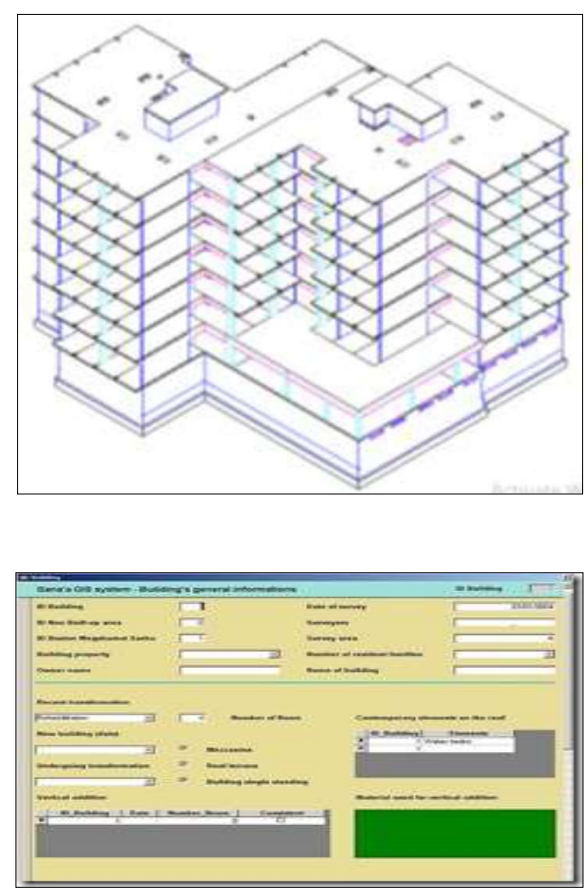

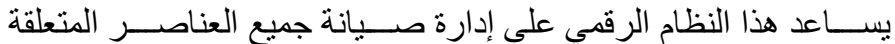

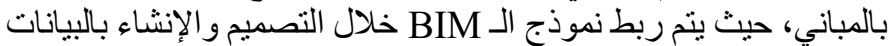

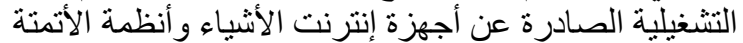

مصادر البيانات المتز امنة البيات

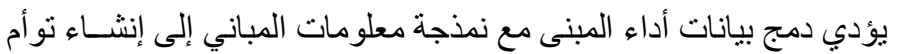

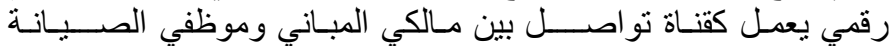
و المستخدمين. نتيجة استخدام البرنامج

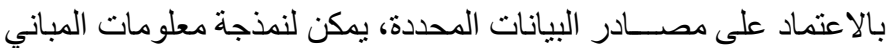

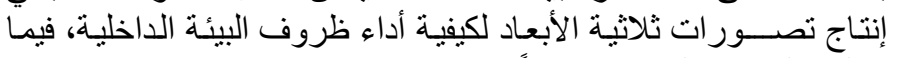

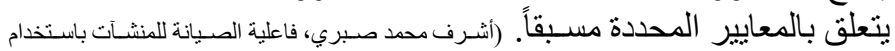

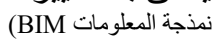

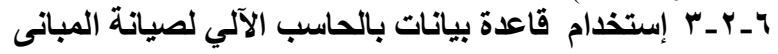

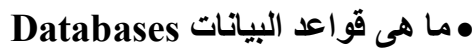

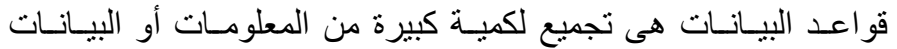

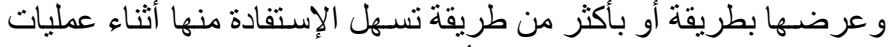

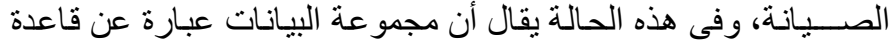

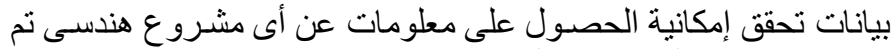

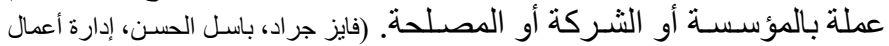

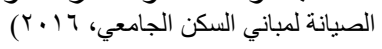




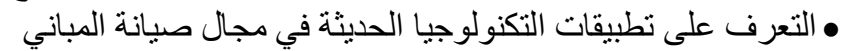

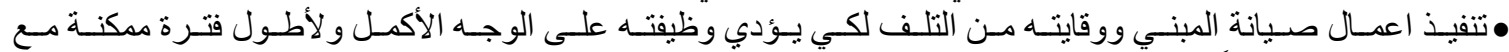
اصلاح العيوب حفاظاً عليه

ع ـفرضية البحث البـ استخدام التكنولوجيا اليجديثة الحيثة المرتبطة ببر امج ذات صلة بأعمال الصيانة يمكن من خلالها معالجة القصور الحالي فى القيام

\section{هـ الاسس والمفاهيم الخاصة بعملية الصنية الصياتة

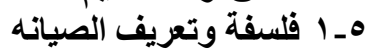

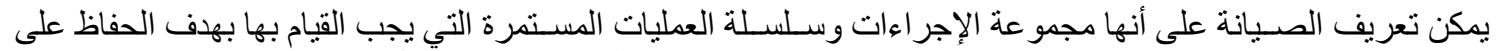

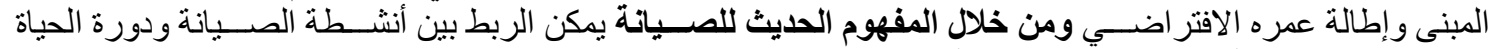

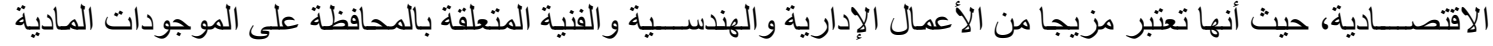

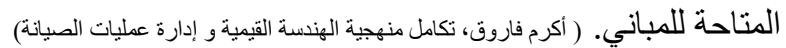

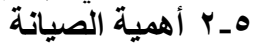
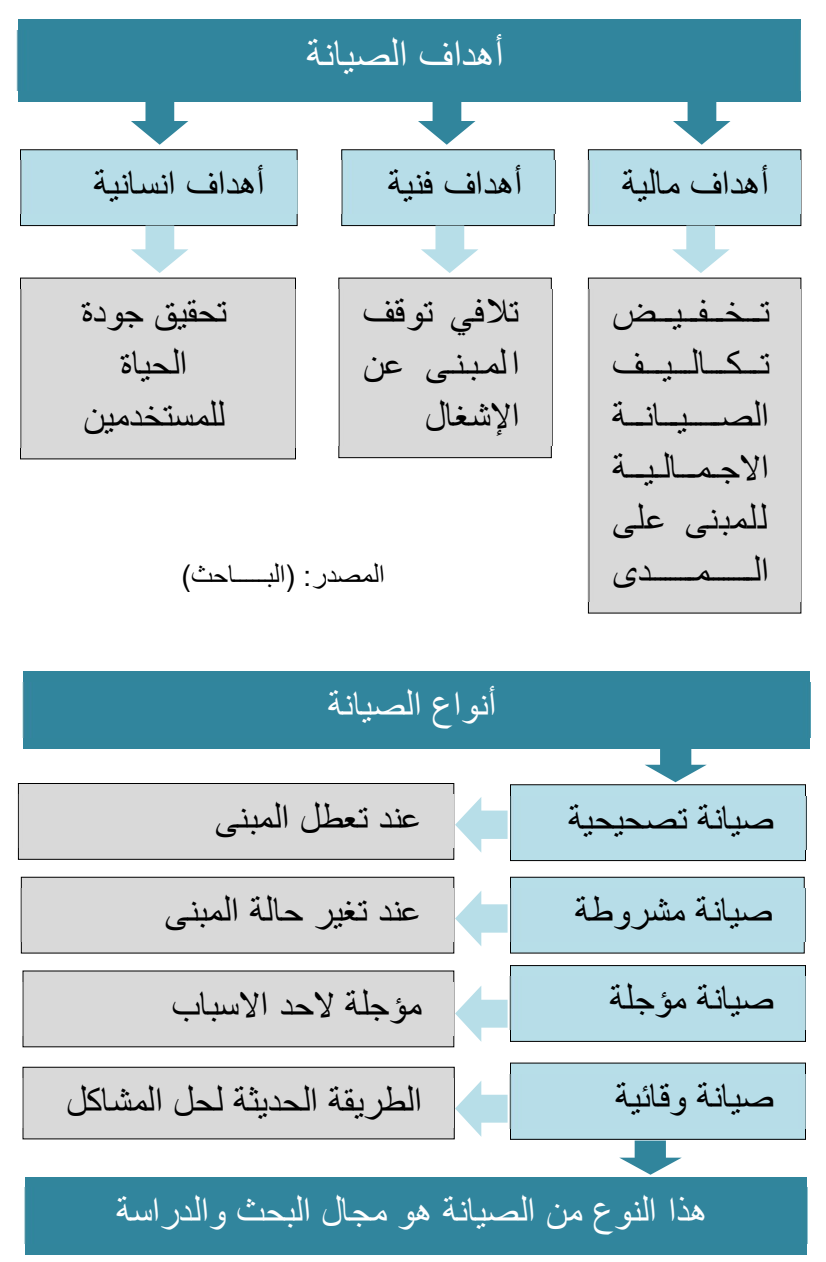

ظلت أعمال صـيانة المبانة الفي لفترة طويلة غبر معروف

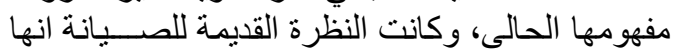

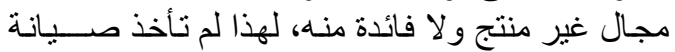

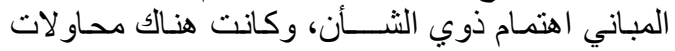

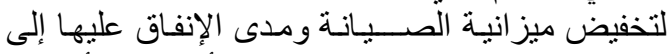

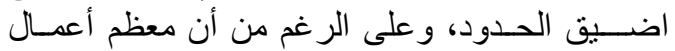

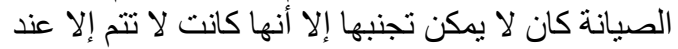

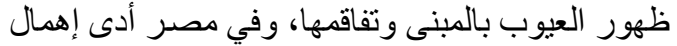

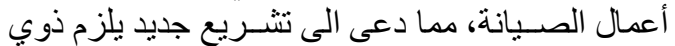

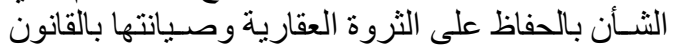

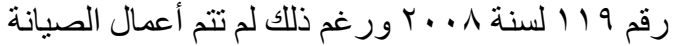

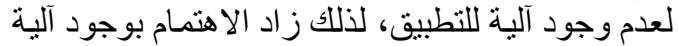

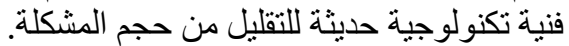
(تامر عوني عبدالقادر، إدارة وصيانة المباني الإدارية، 999 (199 )

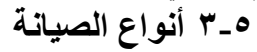

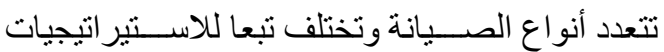

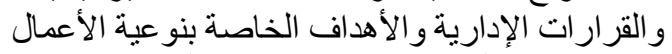

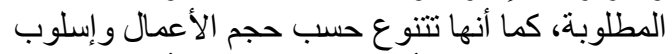

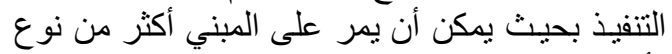

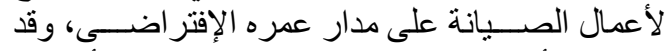

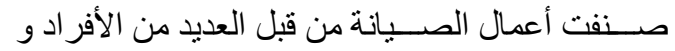

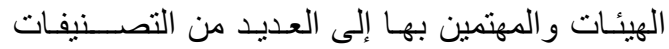

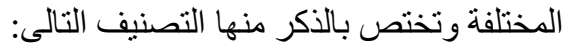

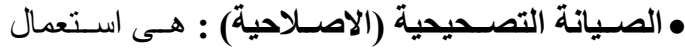

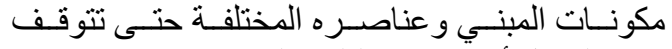

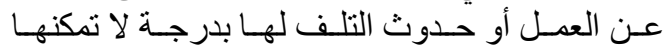
من القيام بالوظائف أو المهام المطلوبة النها منها.

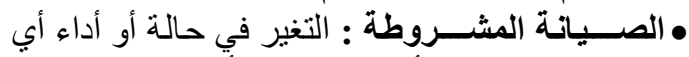

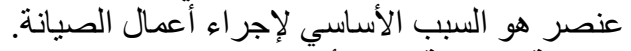
• الصيانة المؤجلة : هى أعمال الصيانة التي كان من الضرالة الصرورى إجر ائها لأي عنصر بهدف المحافظة عليه. 


\title{
BUILDING MAINTENANCE IN EGYPT FROM THE REALITY OF TECHNOLOGICAL DEVELOPMENT
}

\author{
Mostafa Mahmoud Ali Fouda ${ }^{1}$, Magdy Mohamed Kasem ${ }^{\curlyvee}$, Khaled Mostafa Khorshed ${ }^{3}$ \\ Architectural Dept., Faculty of Engineering, Al-Azhar University, Cairo, Egypt. \\ E-mail: archdaily2000@gmail.com
}

\section{ABSTRACT:}

Since the middle of the last century, building maintenance has turned into a self-contained science that has a direct impact on the lives of individuals in the current societies. The field of scientific research has dealt with the issue of maintenance and the need has emerged to use technological techniques in managing maintenance work. Maintenance is considered to have a major and important role in prolonging the life of buildings. The researcher will address in This study is about some techniques of modern technology used in maintenance management and how to benefit from it.

Key Words: (building maintenance technology - maintenance management - modern maintenance techniques)

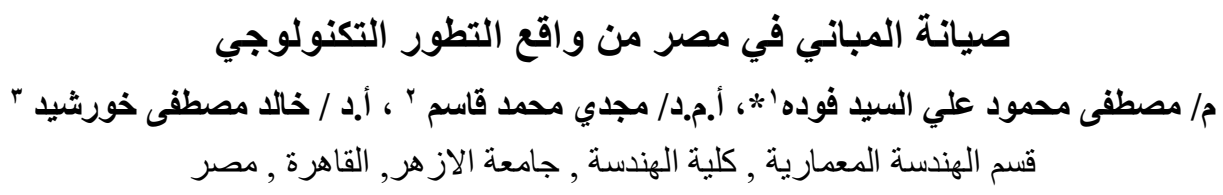

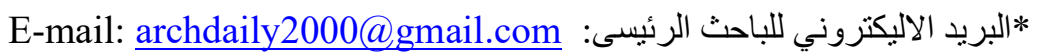

أبت ملخص البحث

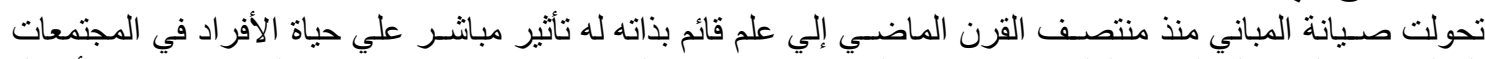

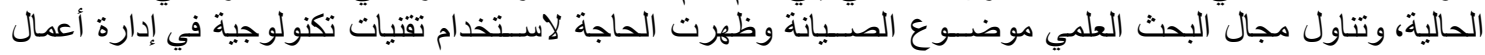

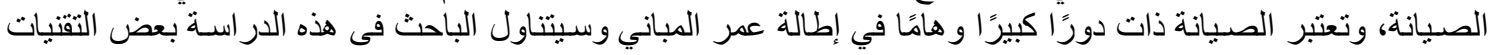

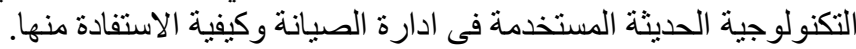

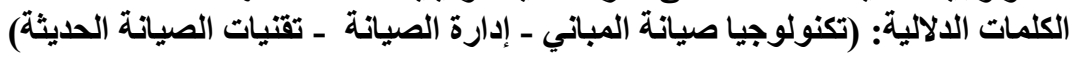

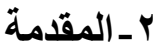

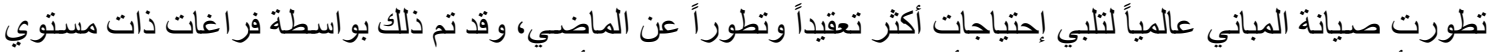

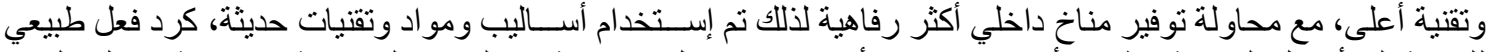

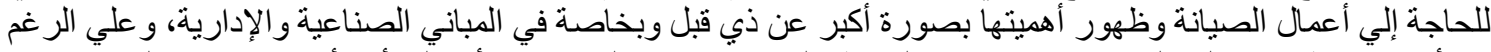

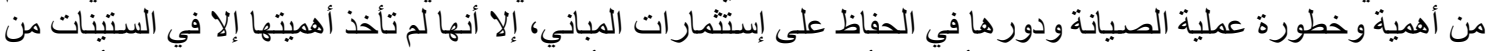

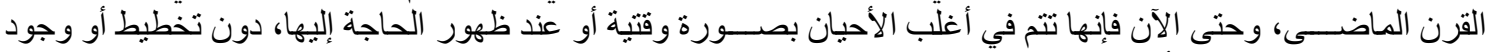

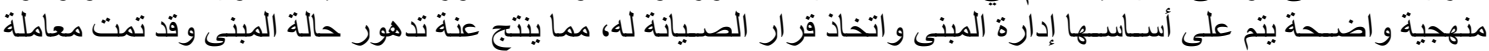

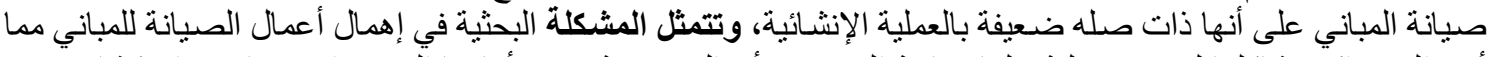

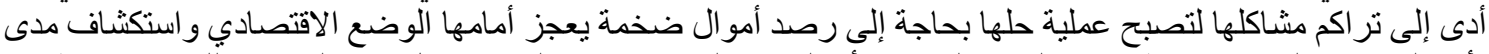

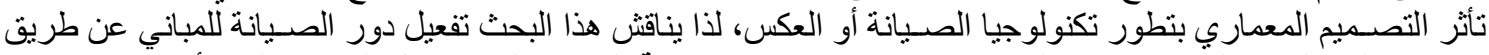

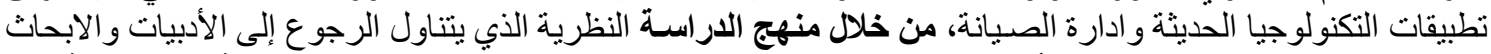

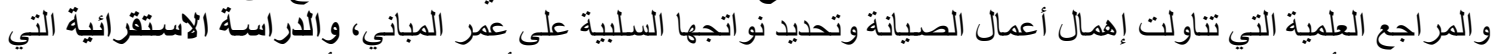

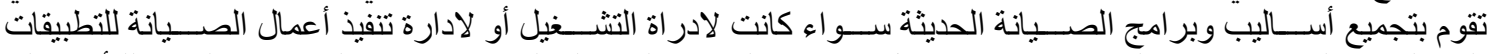

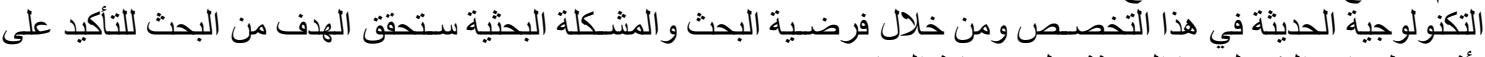

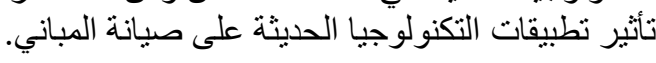

